\title{
DIDÁTICA, PRÁTICAS DE ENSINO E SABERES DOCENTES EM CONSTRUÇÃO
}

\author{
DIDACTICS, TEACHING PRACTICES AND TEACHERS KNOWLEDGE IN \\ CONSTRUCTION
}

\section{DIDÁCTICA, PRÁCTICAS DOCENTES Y CONOCIMIENTOS EN CONSTRUCCIÓN}

Suzana dos Santos Gomes*

\begin{abstract}
Resumo: Este trabalho tem por objetivo investigar o papel da Didática na formação do professor para o Ensino Superior, abordando especialmente a construção da identidade profissional, os saberes docentes e a prática pedagógica de profissionais iniciantes neste nível de ensino. Os dados foram obtidos através da abordagem sócio-histórica, envolvendo estudo de caso de natureza qualitativa, observação participante, análise documental e entrevistas com alunos de mestrado e doutorado. O referencial teórico envolveu pesquisas sobre a formação de professores, sobretudo no campo da Didática do Ensino Superior, entre eles: Veiga e Castanho (2001), Tardif (2002), Cunha (2007), Enricone (2007), e Pimenta e Anastaciou (2010). Nesse estudo, a Didática é entendida como uma possibilidade mediadora entre os conhecimentos específicos e os conhecimentos pedagógicos; a atividade docente é vista como multifacetada e marcada pela complexidade, características que demandam compreensão sobre as origens do professor, sobre o que ele pensa, como interage no espaço profissional e as relações que estabelece com seus alunos no contexto da sala de aula. Considerou-se fundamental identificar a contribuição e o lugar do saber didático na formação e na atividade docente, apreender os processos de produção da identidade profissional e do saber ensinar em situações concretas. Os resultados destacam investimento na formação continuada de professores para o Ensino Superior como um dos fatores determinantes para a qualidade universitária e a emergência da inserção de novas metodologias nos processos de ensino-aprendizagem.
\end{abstract}

Palavras-Chave: Didática. Ensino superior. Identidade. Saberes e práticas.

\begin{abstract}
This paper aims to investigate the role of Didactics in Teacher training on Higher Education, especially approaching the construction of professional identity, the teacher knowledge and the pedagogical practice of novice professionals in at that education level. The data were gathered through a socio-historical approach, involving a qualitative study, participant observation, documental analysis and interviews with master and doctorate students. The theory was based on researches on Teacher training, especially on the field of Didactics on Higher Education, such as Veiga \& Castanho (2001), Tardif (2002), Cunha (2007), Enricone (2007), and Pimenta \& Anastaciou (2010). In that study, Didactics is understood as a mediator possibility between the specific and the pedagogical knowledge; the teacher activity is seen as multifaceted and marked by complexity, whose features demand comprehension on the professor origin, about what they think, how they interact on the professional space and the relationships they establish with their students on the classroom context. We considered fundamental to identify the contribution and the place of didactical knowledge for the training and the teacher activity, apprehending the production processes of professional identity and of teachers knowledge in concrete situations. The results highlighted the importance of fostering continuing Teacher training for Higher
\end{abstract}

*Universidade Federal de Minas Gerais - UFMG. Email: suzanasgomes@fae.ufmg.br 
Education as one of the determining factors for university quality and the emergency of the insertion of new methodologies on teaching and learning processes.

Keywords: Didactics. Higher Education. Identity. Knowledge and Practices

Resumen: El presente trabajo tiene por objetivo investigar el papel de la Didáctica en la formación del profesor para la Enseñanza Superior abordando especialmente la construcción de la identidad profesional, los conocimientos de los profesores y la práctica pedagógica de profesionales principiantes en este nivel de enseñanza. Los datos fueran obtenidos por medio del abordaje sócio-histórico, involucrando estudios de caso de naturaleza cualitativa, observación participante, análisis documental y entrevistas con alumnos de maestría y doctorado. El referencial teórico involucra investigaciones acerca de la formación de profesores especialmente en el campo de la Didáctica de la Enseñanza Superior, entre ellos: Veiga \& Castanho (2001), Tardif (2002), Cunha (2007), Enricone (2007) y Pimenta \& Anastaciou (2010). En eso estudio, la Didáctica es entendida como una posibilidad mediadora entre los conocimientos específicos y los conocimientos pedagógicos; la actividad de enseñanza es vista como polifacética y marcada por su complejidad, características que demandan comprensión acerca de las orígenes del profesor, lo que él piensa, como él interactúa en el espacio profesional y las relaciones que establece con sus alumnos en el contexto del aula. Hemos considerado fundamental identificar la contribución y el lugar del conocimiento didáctico en la formación y en la actividad del profesor, aprehender los procesos de producción de la identidad profesional y del saber enseñar en situaciones concretas. Los resultados destacan la inversión en la formación continuada como uno de los factores determinantes para la cualidad universitaria y la emergencia de la inserción de nuevas metodologías en los procesos de enseñanza-aprendizaje.

Palabras-clave: Didáctica. Enseñanza superior. Identidad. Conocimientos y Práctica.

\section{Introdução}

O presente trabalho é parte de uma pesquisa que investigou o papel da Didática na formação do professor para atuar no Ensino Superior. Tal pesquisa baseou-se no estudo de caso de natureza qualitativa, utilizando como instrumentos para coleta de dados a observação dos alunos em atividades da disciplina Didática, análise de documentos e entrevista semiestruturada com alunos do mestrado e doutorado que foram estimulados a compartilhar suas experiências, saberes e desafios enfrentados na prática docente, tendo em vista o que vivenciam, construindo-se como professor nesse nível de ensino.

A atuação deste profissional nesse contexto tem incentivado vários debates e pesquisas sobre o professor que atua no ensino superior no Brasil. Este trabalho é parte constitutiva de uma pesquisa em Instituições de Ensino Superior (IES) públicas e particulares que investiga como o docente universitário desenvolve-se profissionalmente, que saberes e práticas envolvem sua atuação, ou seja, quem são, o que pensam e o que sabem fazer os professores que atuam no Ensino Superior. Para isso, foram analisados os discursos desses profissionais para, inicialmente, desvelar pontos relacionados à sua visão de competência profissional frente às limitações e às condições de trabalho e, em seguida, focalizar sua prática docente (GOMES, 2012b, 2012c)

Considerou-se fundamental neste estudo dialogar com os professores, pois muitas vezes as propostas para o Ensino Superior fazem abordagens sobre o trabalho docente sem que o próprio docente seja ouvido. Ao se considerar que uma instituição é o resultado 
do que os seus integrantes pensam e agem, a participação do professor e do aluno no Ensino Superior deve ser considerada de fundamental importância.

Pesquisas de âmbito nacional revelam que o investimento do setor privado no Ensino Superior trouxe um aumento do número de docentes. Essa explosão de professores acarretou, dentre outras consequências, a ausência de uma compreensão mais ampla sobre as origens desse professor universitário, o que ele pensa, como interage no seu espaço profissional e com os seus pares. Isso porque os professores, de modo geral, são oriundos dos mais variados cursos, distantes da preparação para a vida acadêmica que o Ensino Superior exige.

Por tudo isso, nos limites deste artigo procurou-se responder: qual é o papel da Didática na formação do professor? Que saberes são necessários para a prática docente no Ensino Superior? Como preparar profissionais iniciantes para o ingresso no Ensino Superior favorecendo a construção de saberes e práticas?

\section{Referencial teórico}

Pesquisas no campo da formação docente no Ensino Superior têm levantado questões sobre as condições pelas quais esses sujeitos ingressam na carreira acadêmica (VEIGA; CASTANHO, 2001; MELLO; OLIVEIRA, 2005; CUNHA, 2007; ENRICONE, 2007; PIMENTA; ANASTASIOU, 2010; GOMES, 2012a, 2012b, 2012c).

Também Cunha, Brito e Cicillini (2006) destacam o papel da Didática do Ensino Superior e ressaltam que 'acordar' o professor universitário é um ritual de passagem e que, portanto, requer cuidados específicos que considerem as singularidades desse nível de ensino.
Coerentemente com essa perspectiva, a Coordenação de Aperfeiçoamento de Pessoal de Nível Superior (CAPES) recomenda o estágio supervisionado na docência como parte das atividades de bolsistas de mestrado e de doutorado, defendendo, assim, a formação pedagógica para aqueles que, realizando cursos de pós-graduação, têm na atividade docente um campo de trabalho possível.

Nesse contexto, a didática tem um papel fundamental: configura-se como uma intervenção contextualizada, crítica e criativa com os sujeitos que a produzem - professores e alunos - em um determinado tempo e lugar. De fato, o desafio que se impõe à prática docente no Ensino Superior consiste na articulação entre as ações didáticas de ensinar e aprender no contexto da sala de aula.

Assim, considera-se fundamental a compreensão da Didática nas dimensões políticas, humana e técnica, além de entendê-la como possibilidade mediadora dos processos de ensino na direção da aprendizagem significado para aquele que ensina e para aquele que aprende.

Além disso, pesquisas no contexto do Ensino Superior têm revelado que nem sempre quem domina conhecimentos teóricos sabe transpô-los para uma situação de aprendizagem. ${ }^{1}$ Nesse sentido, para planejar, gerir e avaliar situações didáticas para o desenvolvimento da autonomia dos alunos, o professor terá que compreender os conteúdos próprios de sua área de atuação, objetos de sua ação didática e, além disso, desenvolver outros saberes docentes.

Dessa maneira, se a docência é sua área de atuação, além das especificidades

\footnotetext{
1 Transposição didática é a expressão designada por Chevellard (1995) para expandir a relação entre a reconstrução de um conhecimento no processo de ensino, isto é, a mediação didática para tornar um conhecimento ensinável.
} 
inerentes aos diferentes campos de conhecimento, a Didática também compõe o quadro da formação, envolvendo conteúdos próprios da prática pedagógica universitária.

No que diz respeito à articulação entre ensino e aprendizagem, Masetto (2003, p. 82) alerta para a necessidade atual de "transposição de paradigmas na ação didática universitária”. O autor propõe a substituição da ênfase no ensino pela ênfase na aprendizagem, de modo que tal mudança demanda que o professor assuma a função de mediador pedagógico, ou seja, de orientador do processo de aprendizagem do aluno.

Em seus estudos, Nóvoa (1995) parte do princípio de que os professores, independentemente do nível de ensino em que atuam, devem diagnosticar o seu próprio contexto de trabalho, tomar decisões, atuar e avaliar sua prática para reconduzi-la do melhor modo possível. Zabala (1998), por sua vez, afirma que, para desenvolver a docência, é preciso dispor de marcos interpretativos, e que a melhoria da prática educativa passa pelo conhecimento e pelo controle das variáveis que nela intervêm. $\mathrm{O}$ autor considera a complexidade do processo ensino-aprendizagem e defende que os professores tenham à disposição e utilizem-se de referenciais que os ajudem a planejar, avaliar e interpretar o que acontece na sala de aula.

O esforço de articulação entre ensino-aprendizagem reafirma a questão da construção da autonomia do aluno. É neste contexto de relações entre a construção da autonomia na aprendizagem universitária que a Didática, campo de conhecimentos vinculado à Pedagogia, ganha força para dimensionar o ensino, ou seja, a docência no Ensino Superior. Assim, frente aos desafios postos para o ensino, o domínio específico de uma área científica do conhecimento por si só não é suficiente. Compete ao professor desenvolver também outros saberes pedagógicos e políticos.

Pesquisas realizadas no campo da Didática têm revelado que os professores chegam à docência na Universidade com impressões variadas sobre o que é ser professor. A maioria deles espelha-se nos professores que foram significativos em suas vidas, isto é, aqueles mestres que contribuíram para a sua formação pessoal e profissional. O desafio que se impõe, então, é de construir a sua identidade de professor universitário, para o qual os saberes da experiência são importantes, mas não bastam.

Entre os autores que têm se debruçado sobre a questão dos saberes que os professores mobilizam quando ensinam, destacam-se Tardif, Lessard e Lahaye (1991), Schön (1995), Shulman (1996) e Tardif (1999). O presente trabalho busca identificar aspectos dos trabalhos citados que representam contribuições significativas como também explicitam algumas diferenças em suas proposições e análises.

Os saberes da experiência são os constituídos no exercício da prática cotidiana da profissão, fundados no trabalho e no conhecimento do meio. "São saberes que brotam da experiência e são por ela validados. Incorporase à vivência individual e coletiva sob a forma de hábitos e de habilidades, de saber fazer e de saber ser” (TARDIF; LESSARD; LAHAYE, 1991, p. 220).

Constata-se que, na análise do saber docente, os autores ressaltam sua complexidade, demonstrando o seu caráter plural. Chamam a atenção para a existência dos saberes da experiência, que não são para e sim da prática, aqueles que têm origem na prática cotidiana do professor em confronto com as condições da profissão. (MARTINS, 2003, 2008; ANDRE, 2008; BAIBICH-FARIA, 2009) 
Como se pode observar, esses autores valorizam os saberes da prática - cultura docente em ação - e que, assim, deixa de ser vista como instância inferior para se transformar em núcleo vital do saber docente.

Schön (1995) oferece contribuições para o estudo do saber dos professores que, segundo ele, criam um conhecimento específico ligado à ação, que só pode ser adequado através do contato com a prática. É um conhecimento pessoal, tácito e não sistemático. Em sua proposta, o autor criou a categoria de professor-reflexivo e o conceito de reflexão-na-ação, segundo o qual o professor analisa e interpreta a sua própria realidade no ato, e o conceito de reflexão-sobre-a-ação, que implica o olhar retrospectivo e a reflexão sobre o que foi realizado.

Os diferentes tipos e modalidades de conhecimento que os professores dominam são estudados por Shulman (1986). Sua contribuição traz ao centro da discussão a questão do conhecimento que os professores têm dos conteúdos de ensino e do modo como estes conteúdos se transformam no ensino. $\mathrm{O}$ autor investiga o que sabem os professores sobre os conteúdos de ensino, onde e quando adquiriram esses conteúdos, como e por que tais conteúdos se transformam no período de formação e como são utilizados na sala de aula, e distingue três categorias de conhecimento de conteúdos que se desenvolvem nas mentes dos professores: "o conhecimento da matéria do conteúdo, o conhecimento pedagógico dos conteúdos e o conhecimento curricular” (SHULMAN, 1986, p. 10).

Nesse sentido, esses estudos identificam os aspectos que podem melhor definir e fortalecer a identidade e a autonomia profissional e que podem, portanto, dar conta da complexidade e especificidade do saber constituído no e para o exercício da atividade docente.

\section{A pesquisa}

A análise da identidade docente e dos saberes construídos na prática demanda conhecermos os professores como sujeitos da pesquisa. Nesse sentido, foi importante saber quem são os professores que atuam no Ensino Superior? Nesse estudo partiu-se de uma amostra de trinta (30) alunos dos cursos de mestrado e doutorado que cursavam a disciplina Didática do Ensino Superior, ingressantes na carreira docente, dos quais $56 \%$ participavam do projeto de iniciação à docência, e 43\% eram professores do Ensino Superior em instituições públicas e privadas.

Essa amostra envolveu professores do sexo masculino e feminino, jovens, com experiência inicial docente na área de formação específica do curso em que ministravam aulas. Dos (30) trinta participantes da amostra, constatou-se que 55\% apresentavam formação acadêmica na área das Ciências Biológicas, da Saúde e Agrárias; 25\% pertenciam à área de Ciências Sociais Aplicadas; 10\% eram oriundos das Ciências Exatas e das Engenharias; $5 \%$ pertenciam à área de Línguística, Artes e Letras; finalmente, 5\% eram da área de Ciências Humanas.

Quanto à titulação dos docentes, 70\% eram doutorandos com mestrado concluído, e $30 \%$ eram mestrandos. Os dados da pesquisa foram obtidos em observação participante, sendo o questionário respondido pelos trinta (30) participantes, visando à coleta de dados sobre identificação, formação acadêmica e experiência profissional. As informações obtidas por meio do questionário foram tabuladas e submetidas a tratamento estatístico. As entrevistas realizadas com 33\% dos participantes foram transcritas e delas foram extraídas as seguintes categorias: identidade, saberes docente, formação, didática e prática docente. 
Trata-se de uma investigação que tem a abordagem sócio-histórica como orientação teórico-metodológica. Essa abordagem enfatiza a compreensão dos fenômenos a partir de seu acontecer histórico, no qual o particular é considerado uma instância da totalidade social. A pesquisa é vista como uma relação entre sujeitos, portanto dialógica, na qual o pesquisador é uma parte integrante do processo investigativo. Assim, por meio da observação participante é possível documentar o não documentado, isto é, desvelar os encontros e desencontros que permeiam o dia a dia do contexto acadêmico, descrever as ações e representações dos sujeitos, reconstruir suas interações, suas formas de comunicação e os significados que são criados e recriados no contexto da sala de aula.

Para Freitas (2002, p.28-29),

A observação é, nesse sentido, um encontro de muitas vozes: ao se observar um evento, depara-se com diferentes discursos verbais, gestuais e expressivos. São discursos que refletem e refratam a realidade da qual fazem parte, construindo uma verdadeira tessitura da vida social. O enfoque sóciohistórico é que principalmente ajuda o pesquisador a ter essa dimensão da relação do singular com a totalidade, do individual com o social.

Como se vê, a abordagem sócio-histórica fornece um conjunto de construtos teóricos e princípios para examinar as questões propostas, como, por exemplo: que sentido e significado os alunos dos cursos de mestrado e doutorado atribuem à Didática do Ensino Superior?; que saberes são construídos por eles no processo de formação docente?; como os alunos da pós-graduação ingressam no ensino superior?; que desafios enfrentam?; como constroem sua identidade docente?

As reflexões advindas da análise desses dados apontam elementos para a implementação de políticas institucionais voltadas para a formação do professor universitário, mediante a defesa de propostas que considerem as peculiaridades e as especificidades da formação para o Ensino Superior.

Os depoimentos dos professores carregam os sentidos e significados que eles atribuem à experiência vivida no Ensino Superior e nas aulas de Didática. Nas entrevistas, os professores compartilharam aspectos da formação, enfocando, entre eles: a opção pela docência, as influências sofridas, a trajetória profissional, a formação inicial, o que suscitou questões, como a carência da formação pedagógica e, ainda, a formação para a docência na pós-graduação. Alguns entrevistados destacaram a aprendizagem advinda da experiência, discutiram sobre o que é ser professor e destacaram os conhecimentos necessários para se exercer a docência. Para preservar a identidade dos participantes da pesquisa foram adotados nomes fictícios.

No cotidiano acadêmico, o professor é desafiado a desenvolver progressivamente saberes oriundos do próprio processo de trabalho. E é exatamente o desenvolvimento desses saberes que exige dele tempo, prática, experiência, entre outros. Em outras palavras, procurou-se averiguar se esses saberes, oriundos da própria prática do professor, eram utilizados na prática cotidiana da sala de aula para administrar os desafios presentes no exercício profissional, dando sentido às situações de trabalho que lhes são próprias.

Sobre os saberes resultantes da prática, assim se posicionaram alguns dos professores $^{2}$ :

Com a prática docente descobri muitas coisas. A experiência de fazer os alunos avaliarem a aula tem me dado elementos muitos ricos. A formação pedagógica que

${ }^{2}$ Adoção de nomes fictícios para professores alunos da disciplina Didática do Ensino Superior. 
eu obtive nas aulas de Didática do Ensino Superior me ensinou a refletir, a examinar as causas, a não ser precipitado. Com ela me tornei um bom ouvinte, aprendi a planejar e aceitar outros posicionamentos (Prof. Antonio).

A experiência que agora desenvolvo adveio da necessidade de mudança que sentia e fui, assim, reorganizando minhas concepções de ensino. Mas creio que, como antecedente deste processo está a insatisfação com a forma de ensinar dos meus professores na Universidade. Inovar, pelo que estou entendendo, não é só ser diferente. [...] Mas trazer alternativas didáticas para os impasses do Curso que envolve o enfrentamento da realidade educacional. Implica também romper com visões tradicionais e a-históricas, incorporando ainda a interação entre teoria e prática (Profa Edna).

Nessa perspectiva, reflexão e processo passam a constituir, nos últimos anos, o eixo de uma tendência na formação considerada como meio de construção de saberes e identidade profissional. A prática docente estimula a visão crítico-reflexiva, além de fornecer ao professor os meios para desenvolver o pensamento autônomo e facilitar a dinâmica de autoformação participada. Estar em formação implica investimento pessoal, trabalho criativo e autônomo com vistas à construção de uma identidade, que é também uma identidade profissional.

Ainda acerca da construção de saberes, deve-se assinalar que o professor como mobilizador de saberes profissionais em sua trajetória constrói e reconhece suas concepções e conhecimentos em diferentes contextos e tempos, conforme os desafios da prática docente. Essas ideias estão presentes nos depoimentos de professores, como

Descobri que existem muitas maneiras para dinamizar o trabalho no ensino superior. Tem sido desafiante esse trabalho porque você tem que recriar formas para atingir o aluno, desenvolver habilidades de leitura, escrita e raciocínio (Prof. Mateus).

E, ainda,

O professor na docência universitária traz consigo experiências variadas do que é ser professor. Essas experiências muitas vezes guiaram sua opção profissional, vão guiar suas escolhas pedagógicas e até mesmo seu relacionamento com os alunos. (Prof. Gustavo)

Os entrevistados falam das influências positivas em sua carreira e destacam a importância da Didática na prática de alguns dos professores. Conforme suas avaliações:

Eu tive bons professores e hoje oriento-me na didática dos professores que me mantinham atento, penso nos recursos que utilizavam. O que deu certo eu procuro fazer com meus alunos (Profa. Amanda).

Os professores que me marcaram foram aqueles que interferiram na minha forma de ver o mundo. Isto foi fundamental para mim. No Ensino Superior tive professores que falavam e ninguém entendia nada. Não gostei de professores que colocaram o conteúdo teórico como verdade pronta e acabada (Prof. Gilberto).

Torna-se importante destacar que os saberes constitutivos da profissão de professor, independentemente do nível de atuação, começam antes e apesar de qualquer formação inicial institucionalizada. O professor aprende uma série de valores profissionais que vão permitir construir uma representação sobre o que é ser professor.

Com base nessas reflexões, parece evidente que toda profissão é um construto social e, como tal, atende a algumas exigências de um dado contexto histórico, bem como contém uma concepção do próprio sujeito sobre 
o que constitui sua profissão. Esse fator está relacionado a um processo de construção identitária.

Em seus trabalhos, Zeichner (1993) aborda o conceito de professor reflexivo e lembra que esse conceito pode significar coisas diferentes. Assim, “A pergunta não é se os professores são reflexivos, mas como estão refletindo e sobre o que estão refletindo". (ZEICHNER, 2000, p. 12)

Nessa perspectiva, a ideia de reflexão como prática, defendida por Zeichner (1993), parece contribuir mais de perto para a construção do sentido do trabalho docente. $\mathrm{O}$ autor ressalta a intervenção entre os professores, enfatizando que assim eles podem se apoiar mutuamente, sustentar o crescimento uns dos outros, olhar para os próprios problemas e compreender que eles têm relação com os outros professores e com a própria estrutura na universidade.

Prosseguindo a reflexão sobre o trabalho docente, para traçarmos o esboço da questão do saber docente, foi importante neste estudo retomarmos mais uma vez as contribuições de Tardif, Lessard e Lahaye (1991). Segundo esses autores, o professor certamente sabe alguma coisa, mas o quê, precisamente? O docente do Ensino Superior sabe planejar aulas? Sabe identificar situações de conflito, que demandam intervenções?

Essas questões se relacionam com o depoimento de uma professora sobre o trabalho desenvolvido por ela:

[...] a primeira coisa que eu faço é conversar com a turma e ver onde eu posso melhorar, como é que eu devo falar para que eles possam entender. O mais importante é o entendimento deles. Eu preciso ouvir dos alunos o que está acontecendo e aí eu tento depois, em cima do que eles falaram, em tento remontar o meu curso (Profa. Solange).
Constatou-se nas entrevistas a necessidade de preparação pedagógica, bem como se verificou a ausência dessa formação na graduação e na pós-graduação. Na maioria das instituições de Ensino Superior, embora seus professores possuam anos de estudos em suas áreas específicas, predomina o despreparo com relação às questões do processo ensino-aprendizagem. De modo geral, os professores não receberam orientações sobre planejamento, procedimentos metodológicos e avaliação.

Nessa direção, pesquisadores das várias áreas de conhecimento entram no campo da docência universitária como decorrência natural e por interesses variados. Por um lado, trazem consigo uma imensa bagagem de conhecimentos em suas respectivas áreas de pesquisa e de atuação profissional; por outro, nunca se questionaram sobre o que significa ser professor.

Sobre essa questão, muitos professores enfatizam a falta de formação pedagógica e apontam a formação continuada como saída. Além disso, destacam o papel da Didática do Ensino Superior tanto para os professores iniciantes da carreira docente como para os antigos.

[...] Todos deveriam fazer o Curso de Didática do Ensino Superior. É muito importante garantir a formação para ser professor. Principalmente na área da saúde. Aprendi a fazer pesquisa, a realizar procedimentos laboratoriais, mas a formação pedagógica para ser professor eu não tive no mestrado não (Profa. Mirtes).

Outro professor destacou:

Um dos focos do mestrado deveria ser a prática docente. Nós temos dificuldades. A gente deveria ter alguma formação pedagógica com professores de Didática. As 
vezes a gente dá um jeito e acaba fazendo, mas isso não é correto, não (Profa. Carla).

Mesmo que a maioria dos professores tenha defendido que não basta conhecer a matéria de ensino para ser professor, esse aspecto mereceu destaque, pois o ponto de partida para a docência envolveu os saberes do campo específico de conhecimento. Só depois de conhecer o conteúdo a ser trabalhado é que se torna possível investir em alternativas para mediar esse conhecimento. Talvez esse fator indique a ênfase, ainda presente, em desenvolver os conteúdos propostos, em uma prática quase de "engessamento" do professor. Poderia se pensar, também, que o princípio do trabalho do professor de educação superior esteja centrado nas informações referentes ao conteúdo específico que ele leciona.

Podendo ser classificado como um saber didático-pedagógico, foi referenciada pelos interlocutores a importância em saber lidar com os imprevistos, com situações nas quais não basta conhecer o conteúdo. Os imprevistos se referiam, dentre outros, ao saber lidar com os alunos, a trabalhar com turmas grandes ou dominar formas de desenvolver os conteúdos. Houve menção a certo despreparo do professor para enfrentar essas situações, sendo atribuída à experiência a capacidade de encontrar soluções para essas questões.

A participação do aluno no processo ensino-aprendizagem, seu envolvimento e o interesse do aluno pelo estudo foram considerados elementos essenciais, e isso transparece no discurso dos professores. O envolvimento de professores e alunos, para uma das professoras, por exemplo, deve ser mais que racional e profissional. Deve haver um envolvimento mais pessoal, um maior comprometimento com a formação do aluno e do aluno com o ensino.

[...] Numa sala de aula em que você tem os alunos que participam, que tem sede de conhecimento, que instigam, que têm vontade de aprender, a aula fica mais interessante, flui naturalmente. Você consegue fazer um trabalho melhor. Até porque você está falando e obtendo retorno dos alunos daquilo que está sendo discutido (Prof. Rafael).

Para que a aula tenha significado pedagógico é preciso possibilitar a construção conjunta e a participação. Por isso, defende-se que os professores sejam pesquisadores do próprio conhecimento, que elaborem, que planejem, conseguindo, assim, orientar seus alunos a também construírem de maneira própria o seu conhecimento, com qualidade formal e política, atingindo aí o sentido educativo da pesquisa.

No entanto, quando falam sobre suas percepções sobre como seria um bom professor, esses docentes afirmam que seria aquele que consegue transformar o conhecimento, a teoria, em algo prazeroso, que consegue contextualizar o conhecimento sem ser pragmático, que gosta da ciência, do conhecimento, que apresenta boa formação acadêmica e se aventura no processo de construção do conhecimento, sabe pesquisar e ensinar a pesquisar, desperta dúvidas e reflexões nos alunos, questiona sua própria prática e concepções de mundo, como se observa nos depoimentos a seguir:

Eu tenho me preocupado em despertar dúvidas nos alunos, provoco reflexões, procuro não dar tudo pronto, não. Eu acho que quando você desperta alguma coisa no aluno ele vai buscar por si só e tem mais interesse. É claro que você tem que abordar os conteúdos sem ficar totalmente preso ao plano de ensino (Prof. Sofia).

E mais,

O bom professor é aquele que está constantemente na dúvida, que se questiona 
muito, sabe? Porque o questionamento da prática é o que move a busca de qualidade. Então em primeiro lugar, tem que gostar da sala de aula, tem que ser apaixonado pela sua matéria e estar constantemente nesse processo de dúvida, de questionamento da própria prática pedagógica (Prof. Tadeu).

Ao ser abordada a identidade docente e os saberes que ele deve mobilizar, houve destaque para figura do aluno-professor ingressante na carreira na construção dessa identidade. Os professores entrevistados, ao falarem de si, o fizeram tendo como parâmetro o aluno. Existe uma expectativa por parte dos alunos sobre o que compete ao professor, e, de certa forma, essa expectativa vem servindo como balizadora da construção identitária do professor. Esse aspecto ficou evidente quando foi perguntado aos professores se o aluno exerce influência ou não no seu trabalho docente. É o que se pode perceber nos depoimentos abaixo:

Acredito que os alunos me ajudam a entender melhor o meu compromisso político como professor. Para mim é importante a opinião deles sim. Mas eu cobro responsabilidade deles também (Prof. Edson).

Cada aluno é um ser único, com necessidades e características pessoais. Nunca consegui repetir um trabalho realizado numa turma do mesmo jeito. Cada turma tem o seu jeito de ser e reagir diante do trabalho proposto. Os resultados terão estreita relação com o perfil da turma (Profa. Isaura).

Torna-se importante ressaltar que alguns problemas foram evidenciados nas entrevistas: a intensificação do trabalho do professor, o número excessivo de alunos na turma e o número de aulas que o professor tem que assumir, dentre outros, são fatores que dificultam uma proximidade mais efetiva entre professor e aluno. Para muitos professores, conhecer e memorizar os nomes dos alunos já é uma façanha. Identificar suas particularidades e situações contextuais torna-se bastante difícil. Mesmo assim, os professores reconhecem a importância de superar esses entraves. Percebem que, quando os professores se aproximam dos alunos com flexibilidade, afetividade e respeito, as condições para ensinar e aprender se tornam mais efetivas.

Finalmente, a abordagem dos saberes mencionados pelos professores, torna evidente que os não saberes são tão importantes quanto os saberes. O sentimento de incompletude e os sucessos constituem o professor em igual medida. Não existem garantias sobre o que vai dar certo ou não. As mesmas características que fazem com que um professor seja qualificado como bom professor, para uma turma, podem ser o que o desqualifica para outra. Essas são, muitas vezes, as contradições da prática docente. Assim, os saberes mais importantes são aqueles que ajudam o professor a compreender melhor a si mesmo no espaço pedagógico.

\section{Algumas considerações}

Pretendeu-se com este artigo analisar o universo formativo do professor do ensino superior, levantando alguns pressupostos sobre o papel da Didática na formação do professor, abordando especialmente a construção da identidade profissional, os saberes docentes e a prática pedagógica de profissionais iniciantes nesse nível de ensino.

A Didática, nesse estudo, foi concebida como espaço de concretização do trabalho docente, norteadora da relação pedagógica entre professor e aluno. Assim, a ênfase no ensino da Didática justifica-se por ser este um dos espaços no qual se desenvolvem as práticas pedagógicas com o objetivo de possibilitar ao aluno a construção de conhecimentos e, 
consequentemente, a formação no campo da docência.

Coerentemente com essa perspectiva, o ensino da Didática deve possibilitar aos futuros professores conhecimento da realidade para nela interferirem conscientemente. Tratase de uma disciplina cujo papel central consiste em mobilizar o professor para resgatar outros saberes, a relacioná-los no tempo e no espaço num processo de reflexão constante, ou seja, antes, durante e após a organização e o desenvolvimento do trabalho pedagógico.

Nesse sentido, este trabalho reafirma a complexidade da Didática e destaca sua dimensão de totalidade. Dimensão esta que tem na prática pedagógica crítica a provisoriedade, a imprevisibilidade, o caráter investigativo e a dialogicidade como condições para trabalhar a dialética como método propulsor das inferências analíticas.

Os resultados da pesquisa permitiram ainda evidenciar a influência da tendência pedagógica progressista no imaginário e na prática docente dos jovens professores, constituindo significativamente a construção de suas percepções sobre a docência no Ensino Superior.

O diálogo com as entrevistas e com o referencial teórico possibilitou algumas considerações sobre como os docentes das diferentes áreas do conhecimento se preparam para o exercício da docência. Os professores demandam maior investimento na formação docente, nos cursos de especialização e no mestrado, uma vez que no doutorado a ênfase é colocada na pesquisa.

Em seus depoimentos, os jovens docentes valorizaram a formação pedagógica obtida especialmente na disciplina Didática do Ensino Superior e apresentaram a formação continuada como uma possibilidade de se manterem atualizados frente ao seu campo de conhecimento e, além disso, dialogar com os saberes pedagógicos que permeiam o contexto do Ensino Superior.

A construção de um referencial de docência e de educação não se resume a uma única possibilidade. Existe uma dinamicidade nesse processo de construção identitária que é situada e se transforma devido à trajetória vivida pelos professores.

De modo geral, os jovens professores estão investindo na relação com os alunos e estão conscientes de que o aluno é um interlocutor importante. Nesse contexto, destacam-se as dimensões política, humana e técnica.

O espaço de atuação do professor e os saberes que mobilizam também se mostram significante para a sua construção identitária. A identidade profissional foi claramente entendida como processual e sujeita a um contexto histórico.

Finalmente, cabe assinalar que os resultados obtidos neste estudo podem contribuir para compreender a relação pedagógica que ocorre no Ensino Superior, além de apontar a importância da Didática na formação docente.

Espera-se, ainda, que este estudo aponte elementos que ajudem a repensar a formação continuada dos professores e que sinalize para os elaboradores e proponentes de políticas públicas a urgência na formulação de políticas de formação permanente capazes de promover capacitação teórico-metodológica, lembrando que os professores se encontram numa situação de aprendizes desses novos pressupostos pedagógicos.

\section{Referências}

ANDRÉ, M. Tendências da pesquisa e do conhecimento didático no início dos anos 2000. In.: EGGERT, E. (Org.). et al. Trajetórias e processos de ensinar e aprender: didática eformação deprofessores: 
livro 1. Porto Alegre: EDIPUCRS, 2008. p. 487-499.

BAIBICH-FARIA, T. M. A dimensão teórica da formação dos formadores em didática e práticas de ensino: influências no pensamento contemporâneo e repercussões nas práticas de formação. Avaliação, Campinas, vol.14, n.3, 727-753, nov. 2009.

CUNHA, A. M. de O; BRITO, T. R.; CICILLINI, G. A. Dormi aluno (a), acordei professor (a): Interfaces da Formação para o Exercício do Ensino Superior. In: $29^{\mathrm{a}}$ REUNIÃO ANUAL DA ANPED, 29, 2006, Caxambu. Anais eletrônicos... Caxambu, 2006. Disponível em: <http://www. anped.org.br/reunioes/29ra/trabalhos/ trabalho/GT11-2544--Int.pdf>. Acesso em: 7 out. 2012.

CUNHA, M. I. da. (Org.). Reflexões e práticas em pedagogia universitária. Campinas: Papirus, 2007.

ENRICONE, D. A universidade e a aprendizagem da docência. In: CUNHA, M. I. da. Reflexões e práticas em pedagogia universitária. Campinas: Papirus, 2007, p. 145-159

FREITAS, M. T. A. A abordagem sóciohistórica como orientadora da pesquisa qualitativa. Cadernos de Pesquisa, São Paulo, n. 116, p. 21-39, jul. 2002.

GOMES, S. S. Práticas docentes e processos de Formação. Revista Educação, Rio Grande do Sul, v.35, p.414 - 423, 2012a.

Tornar-se professor para o Ensino Superior: didática, práticas de ensino e saberes em construção. In: Ensino Superior: Inovação e Qualidade na Docência. Porto: Edição CIIE - Centro de Investigação e Intervenção Educativas, 2012b, p. 76307644.
Letramentos, Formação de Professores e Mediação Pedagógica no Ensino Superior. In: VII Congresso Iberoamericano de Docência Universitária: Ensino Superior-Inovação e Qualidade. Anais... Porto, 2012.

MARTINS, P. L O. Didática teórica/ didática prática: para além do confronto. 9. ed. São Paulo: Loyola, 2008.

A didática e as contradições da

prática. 3. ed. Campinas: Papirus, 2003.

MASETTO, M. T. Docência Universitária: repensando a aula. In: TEODORO, A.; VASCONCELOS, M. L. (Orgs.). Ensinar e aprender no ensino superior: por uma epistemologia da curiosidade na formação universitária. São Paulo: Cortez, 2003, p. 79-108.

MELLO, R. M. A. V. de; OLIVEIRA, A. M. A Didática de Ensino Superior no Processo de Formação Pedagógica nos Cursos de Pós-Graduação da Universidade Federal de Viçosa (UFV) e Universidade Federal de Minas Gerais (UFMG). In: VIII CONGRESSO ESTADUAL PAULISTA SOBRE FORMAÇÃO DE EDUCADORES, 2005, São Paulo. Anais... São Paulo: Universidade Estadual Paulista (UNESP), 2005. p. 63-70.

NÓVOA, A. Profissão professor. 2. ed. Porto: Porto Editora, 1995.

PIMENTA, S. G.; ANASTASIOU, L. das G. C. Docência no ensino superior. São Paulo: Cortez, 2010.

SCHÖN, D. A. Formar professores como profissionais reflexivos. In: NÓVOA, A. Os professores e a sua formação. Lisboa, Portugal: Dom Quixote, 1995.

SHULMAN, L. Just in case: reflections on learning from experience. In: COLBERT, J., TRIMBLE, K., DESBERG, P. (Eds.). 
The case for education: contemporary approaches for using case methods. Needham Heights, Massachusetts: Allyn \& Bacon, 1996, p.197-217.

Those who understand: Knowledge growth in teaching. In: Educational Researcher, n. 15, p. 4-14, 1986.

TARDIF, M. Saberes docentes e formação profissional. Petrópolis: Vozes, 2002.

dos professores e e $\begin{array}{r}\text { profissionais } \\ \text { conhecimentos }\end{array}$
universitários. Rio de Janeiro: PUC, 1999.

TARDIF, M.; LESSARD, C.; LAHAYE, L. Les enseignants des ordres d'enseignement primaire et secondaire face aux savoirs. In: Esquisse d'une problématique du savoir enseignant. Sociologie et Societés, vol XXIII, n. L, Printemps, 1991, p.55-69.

VEIGA, I. P., A. \& CASTANHO, M. E. L. M. (Orgs.). Pedagogia universitária: a aula em foco. 2. ed. Campinas: Papirus, 2001.

ZABALA, A. A prática educativa: como ensinar. Porto Alegre: Artmed, 1998.

ZEICHNER, K. M. Formação de Professores: contato direto com a realidade da escola. In: Revista Presença Pedagógica, v. 6, n. 34, p. 5-15, 2000.

A formação de professores: ideias e práticas. Lisboa: Educa, 1993. 